\title{
Clinical characteristics of Chlamydia trachomatis infections in a general outpatient department of obstetrics and gynaecology in the Netherlands
}

\author{
C J Bax, P M Oostvogel, J A E M Mutsaers, R Brand, \\ M Craandijk, J B Trimbos, P J Dörr
}

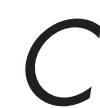
hlamydia trachomatis infections (CTI) are the most common sexually transmitted infections. ${ }^{1}$ CTI in women may cause pelvic inflammatory disease (PID) and subsequently result in tubal factor infertility and ectopic pregnancy. ${ }^{2}$ Finally, CTI in pregnancy may cause neonatal conjunctivitis and pneumonia. ${ }^{3}$ Approximately $70 \%$ of the CTI in women are asymptomatic. The prevalence in asymptomatic obstetric and gynaecological patients in Europe ranges from 0.8 to $4.8 \% .{ }^{45}$ Intrauterine manipulations such as curettage and a hysterosalpingogram in women with a CTI may cause PID as well. ${ }^{6}$ In the Netherlands there are no general policies for intrauterine manipulations. We would like to establish general policies to prevent intra-abdominal CTI. Therefore, information about the clinical aspects of CTI, patient characteristics, and data on the prevalence of CTI in an outpatient department of obstetrics and gynaecology are needed.

\section{METHODS}

From June 1996 to September 1997, new patients attending the outpatient department of obstetrics and gynaecology of the Westeinde Hospital were requested to participate in the study. Approval was obtained by the ethics committee. The Westeinde Hospital is an inner city hospital, with a high percentage of patients of different ethnic origin. After informed consent a questionnaire was completed and a gynaecological examination was performed.

For detection of CTI two methods were used:

(i) A probe hybridisation assay from a urethral, an endocervical and an anorectal swab (PACE 2 assay) (Gen-Probe). Swabs were analysed within 24 hours according to Gen-Probe's packet insert instructions.

(ii) Amplification of CT-rRNA by transcription mediated amplification (TMA) in urine samples with the Gen-Probe AMP CT assay. Urine specimens were collected before swab specimens were gathered and stored at $+4^{\circ} \mathrm{C}$ The urine was analysed on a weekly basis according to Gen-Probe procedures.

When either swab or urine analysis was positive, a patient was considered positive for CTI at the time of sampling.

\section{Statistical analysis}

For descriptive purposes we used cross tabulations. To estimate the probability of chlamydial infections as a function of the various possible risk factors we used a logistic regression model. Risk factors, as found in the literature and assessed by the questionnaire and gynaecological examination were entered into the model after which a backwards elimination was performed. Based on the final model we computed the effects of the remaining risk factors as an estimated odds ratio and its associated 95\% confidence interval.

\section{RESULTS}

During the study period 1684 patients were enrolled. A total of 276 patients refused participation for different reasons $(16.4 \%)$, data on 40 patients $(2.4 \%)$ could not be analysed (incomplete data). With regard to age nonresponder analysis did not reveal significant differences with responders. Data on 1368 patients were examined (table 1A). Sixty two patients $(4.5 \%)$ were found to be positive by DNA probe and/or urine analysis. Of the 62 patients with a CTI the DNA probe was positive in 48 cases. Fifteen $(24.2 \%)$ patients with a positive DNA probe turned out to be negative in urine analysis. Of the CTI patients 45 were found positive in urine analysis. Twelve (19.4\%) CTI patients were detected by positive urine test only. Table IB shows the sampling sites at which the CTI patients were found positive by DNA probe.

Table 2 shows the number of CT infected women, the number of women tested and the according prevalence for various risk factors. The CT prevalence was inversely associated with age. An increase of age of 1 year reduces the probability of infection by $10 \%$ (OR 0.90 , $95 \%$ CI 0.87 to $0.94, \mathrm{p}<0.001$ ).

There was also a significant association with postcoital bleeding. In terms of relative risk the probability of a CTI in patients with postcoital bleeding is 2.6 times as high compared to patients without this complaint (OR 2.6, 95\% CI 1.06 to $6.6, \mathrm{p}<0.04)$.

\section{DISCUSSION}

The overall prevalence of CTI in our outpatient department of obstetrics and gynaecology was $4.5 \%$, according with other European studies. ${ }^{45}$ Similar risk factors as identified in other populations were independently associated with $\mathrm{CT}^{4}{ }^{47}$ As found in other studies we found significantly higher prevalences in younger women. If women only under 30 years of age had been tested we would

Table 1 Results of Gen-Probe PACE 2 assay and the AMP CT assay in the detection of Chlamydia trachomatis (n)

\begin{tabular}{lccrr}
\hline & \multicolumn{2}{c}{ Amplified CT (urine) } \\
\cline { 2 - 5 } PACE 2 DNA probe & Negative & Positive & $\begin{array}{l}\text { Not } \\
\text { determined }\end{array}$ & Total \\
\hline (A) Overall results & 1223 & 12 & 73 & 1308 \\
Negative & 15 & 31 & 2 & 48 \\
Positive & 10 & 2 & - & 12 \\
Not determined & 1248 & 45 & 75 & 1368 \\
Total & & & &
\end{tabular}

(B) Specification of positive sampling sites of the DNA probe Endocervical Urethral

Anorectal

Endocervical/urethral

Endocervical/anorectal

Endocervical/urethral/anorectal Urethral/anorectal

Unknown

\begin{tabular}{rrrr}
9 & 12 & 1 & 22 \\
0 & 6 & 0 & 6 \\
3 & 0 & 0 & 3 \\
2 & 7 & 1 & 10 \\
1 & 0 & 0 & 1 \\
0 & 1 & 0 & 1 \\
0 & 1 & 0 & 1 \\
0 & 4 & 0 & 4 \\
\hline
\end{tabular}


Table 2 Prevalence in relation to the characteristics of the women enrolled in the trial

\begin{tabular}{|c|c|c|c|c|}
\hline & $\mathrm{CT}$ positive (n) & Tested (n) & Prevalence (\%) & $\mathrm{p}$ Value \\
\hline Age (years) & & & & $<0.001$ \\
\hline$<20$ & 12 & 76 & 15.8 & \\
\hline $20-29$ & 34 & 490 & 6.9 & \\
\hline $30-39$ & 11 & 461 & 2.4 & \\
\hline $40-49$ & 5 & 233 & 2.1 & \\
\hline $50-59$ & 0 & 72 & 0 & \\
\hline $60-69$ & 0 & 20 & 0 & \\
\hline 70-79 & 0 & 12 & 0 & \\
\hline$>80$ & 0 & 1 & 0 & \\
\hline Unknown & 0 & 3 & 0 & \\
\hline Postcoital bleeding & & & & $<0.04$ \\
\hline Yes & 6 & 59 & 10.2 & \\
\hline No & 52 & 1241 & 4.2 & \\
\hline Unknown & 4 & 68 & 5.9 & \\
\hline Ethnic origin & & & & NS \\
\hline European & 20 & 568 & 3.5 & \\
\hline Mediterranean & 10 & 275 & 3.6 & \\
\hline African & 4 & 51 & 7.8 & \\
\hline Creole & 5 & 67 & 7.5 & \\
\hline Hindu & 12 & 236 & 5.1 & \\
\hline Asian & 3 & 48 & 6.3 & \\
\hline Hispanic & 3 & 27 & 11.1 & \\
\hline Other/unknown & 5 & 96 & 5.2 & \\
\hline Contraceptive method & & & & NS \\
\hline Non & 32 & 733 & 4.4 & \\
\hline Condom & 4 & 97 & 4.1 & \\
\hline Oral contraceptive & 22 & 324 & 6.8 & \\
\hline Other & 3 & 162 & 1.9 & \\
\hline Unknown & 1 & 52 & 1.9 & \\
\hline
\end{tabular}

have found approximately $75 \%$ of the CTI patients. If women only under 40 years of age had been tested we would have missed only five patients $(8.1 \%)$. In the United States population screening is advised for women 15-24 years of age, other studies advise age based screening for women under 30 years of age. ${ }^{58}$ To prevent complications it might be sensible to screen women in the fertile age $(<40)$.

Our study confirms the association between CTI and postcoital bleeding. However, since all patients with the complaint of postcoital bleeding and a CTI were under 30 years of age, this did not help to reveal more CTI patients than age based screening alone.

We could not confirm the relation between CTI and ethnic origin as described in other studies, in which a significantly higher prevalence was found in women from Suriname and the Netherlands Antilles.' But we do see a trend in a similar direction. An even distribution of CTI was found among patients using condoms or no contraceptive methods. Other studies have described lack of barrier contraceptive as a risk factor. ${ }^{10} \mathrm{~A}$ slightly higher prevalence was found in women using oral contraceptives.

Nearly half of the CTI patients (44\%) were detected by only one of the two diagnostic tests.

Since no discrepant analysis was performed some false positive or negative results cannot be excluded. With respect to the sampling site of the DNA probe we found that most CTI patients were found positive on the endocervical sampling site (34 patients). Eighteen patients were found positive at the urethral sampling site. It is remarkable that six patients were found positive at the anorectal sampling site (table 1B). For women it is advised to test urine or a urethral specimen in combination with an endocervical specimen. ${ }^{11}$ Other studies found the vaginal introitus also a representative site to detect CTI, with the advantage of being non-invasive. ${ }^{12}$ Anorectal swabs should only be obtained in women at high risk of being infected. We would have missed three CTI patients if we had used only the endocervical swab and the urine analysis. These three patients were found positive by anorectal swab only. If we had used only the endocervical and urethral swab we would have missed 15 CTI patients ( 12 patients only positive by urine analysis and three patients only positive by anorectal swab with negative urine analysis). Although population screening on CTI with urine analysis seems to be an easy method, we conclude that analysis of urine as well as endocervical specimens are essential for determination of prevalence of CTI in women. Although DNA amplification methods used on urine specimen are reported to be so sensitive that they may reflect positivity at the endocervical sampling site, our study shows discrepancies. Therefore, both analyses are comple- mentary. Cost effectiveness analysis will show whether age based screening and/or antibiotic prophylaxis before intrauterine manipulations will be indicated.

\section{ACKNOWLEDGEMENTS}

We thank Professors J B Vandenbroucke and O P Bleker for reviewing this paper and Claire Peters for her help in processing the data.

\section{CONTRIBUTORS}

CJB, research fellow, writer of the manuscript; PMO, microbiologist, supervisor laboratory analysis; JAEMM, analyst, supervisor laboratory analysis; RB, statistician, senior lecturer; $\mathrm{MC}$, researcher, collector of clinical data; JBT, professor, supervisor of the study; PJD, senior consultant, supervisor of the study.

Sex Transm Infect 2002;78:e6

(http://www.sextransinf.com/cgi/content/full/ $78 / 6 / \mathrm{e} 6$

\section{Authors' affiliations}

C J Bax, M Craandijk, P J Dörr, Department of Obstetrics and Gynaecology, Medical Centre Haaglanden, Westeinde Hospital, The Hague, Netherlands

C J Bax, J B Trimbos, Department of Gynaecology, Leiden University Medical Centre, Netherlands

P M Oostvogel, J A E M Mutsaers,

Department of Medical Microbiology, Medical Centre Haaglanden, Westeinde Hospital, The Hague, Netherlands

R Brand, Department of Medical Statistics, Leiden University Medical Centre, Netherlands

Correspondence to: Caroline J Bax, Department of Obstetrics and Gynaecology, Medical Centre Haaglanden, Westeinde Hospital, PO Box 432, 2501 CK The Hague, Netherlands:

c.bax@mchaaglanden.nl

Accepted for publication 24 July 2002

\section{REFERENCES}

1 Gerbase AC, Rowly JT, Heymann DHL, et al. Global prevalence and incidence estimates of selected curable STDs. Sex Transm Infect 1998;74(Suppl I):12-16.

2 Cates W, Wasserheit JN. Genital chlamydial infections: epidemiology and reproductive sequelae. Am J Obstet Gynecol 1991:164:1771-81.

3 Schachter J, Grossman M, Sweet RL, et al. Prospective study of perinatal transmission of Chlamydia trachomatis. JAMA 1986;255:3374-7.

4 Warszawski J, Meyer L, Weber P. Criteria for selective screening of cervical Chlamydia trachomatis infections in women attending private gynecologic practices. Eur J Obs Gyn Reprod Biol 1999;86:5-10

5 Macmillan S, McKenzie H, Flett G, et al. Which women should de tested for Chlamydia trachomatis? Br J Obstet Gynaecol 2000; 107: 1088-93

6 Penney GC, Thomson M, Norman J, et al. A randomized comparison of strategies for reducing infective complications of induced abortion. Br J Obstet Gynaecol 1998; 105:599-604

7 Stergachis A, Scholes D, Heidrich FE, et al. Selective screening for Chlamydia trachomatis infections in a primary care population on women. Am J Epidemiol 1993;138: 143-53.

8 Centers for Disease Control and Prevention. Recommendations for the prevention and management of Chlamydia trachomatis infections, 1993. MMWR Morb Mortal Wkly Rep 1993;42(RR-12): 1-39. 
9 Van den Hoek JAR, Mulder-Folkerts DKF, Courtinho RA, et al. Opportunistische screening op genitale infecties met Chlamydia trachomatis onder de seksueel actieve bevolking van Amsterdam. I. Meer dan $90 \%$ deelname en bijna $5 \%$ prevalentie. Ned Tiidschr Geneeskd 1999;143:668-72.
10 Handsfield $\mathrm{HH}$, Jasman $\mathrm{LL}$, Roberts PL, et al. Criteria for selective screening for Chlamydia trachomatis infections in women attending family planning clinics. JAMA

1986:225:1730-4.

11 Brokenshire MK, Say PJ, van Vonno AH, ef al. Evaluation of the microparticle enzyme immunoassay Abbott IMx Select Chlamydia and the importance of urethral site sampling to detect Chlamydia trachomatis in women.

12 Wiesenfeld HC, Heine RP, Rideout A, et al. The vaginal introitus: a novel site for

Chlamydia trachomatis testing in women. Am J Obstet Gynecol 1996;174:1542-6. 